\title{
Computerized simulation of thermal behaviour during forging sequences
}

\author{
S. HOLLARD and J.-L. NOYES \\ ARDEM-FORTECH/AIRFORGE, BP. 173, 09103 Pamiers, France
}

\begin{abstract}
In the field of Hot closed die forging by thermomechanical treatment of high sensibility metallurgical alloys, the final metallurgical structure depends directly of mechanical ( $\varepsilon, \stackrel{\sharp}{\varepsilon} \ldots)$ and thermal ( $T$... ) variables.

Recently, the possibility to couple the mechanical and the thermal behaviour in the computerized simulation of forging sequences makes stronger the predictiv aspect of such softwares.

Some examples will show the importance of this combined point of view.

Industrial applications give very interesting results. They show also the necessity to modelize very accurately thermal exchanges by convection, conduction and radiation.
\end{abstract}

\section{COMPUTERIZED SIMULATION AND FORGING OF THERMOMECHANICAL ALLOYS :}

Generally speaking, all hot forming is thermomechanical processing. However this term is normally used only for specific applications when it is necessary to select and control explicitly deformation and thermal conditions during the process in order to obtain or improve mechanical properties on final products.

In the field of FORTECH/AIRFORGE products we are more specifically concerned by titanium alloys and Nickel based superalloys. A large part of these alloys are used for jet engines components and final mechanical properties are directly in correlation with the metallurgical microstructure.

This one is a consequence of the thermomechanical history from the elaboration to the final forging sequence.

As long as we are concerned by these types of applications, the aim of the forging manufacturer is to control final product properties by controling strain and thermal conditions at every stepduring forging process. 
As exposed in figure 1, this way combines two approaches :

- a metallurgical one : knowledge of the metallurgical behaviour in terms of recrystallization laws, allotropic transformation, and pricipitation.

- a mechanical and thermal one : knowledye of rheological and thermal parameters is required.

\section{CALCULATION AND EXPERIMENTAL PARAMETERS}

From the forging manufactures point of view the problem is to determine experimental parameters which are a guarantee of good results quality.

The introduction of thermal conditions coupled to mechanical calculations opens a new large development area. In the same time, we need to determine a wide range of experimental parameters. If we consider FORGE 2 a software developped by the french Laboratory CEMEF we have to precize :

\section{- Flow curves :}

The material is supposed to be viscoplastic according to the Norton hiff model :

$$
\sigma=K 0 e^{\beta / T}(\sqrt{3} \dot{\bar{\varepsilon}})^{m-1} \dot{\bar{\varepsilon}}
$$

where $\quad K, K_{0}, \beta, m$ have to be experimentaly determined

- Friction :

Friction is considered as a viscoplastic boundary layer :

$$
\begin{gathered}
\tau=-\alpha K_{0} e^{\beta / T}|\Delta V| /|\Delta V|^{1-P} \\
\alpha, p \text { are obtained through ring compression test }
\end{gathered}
$$

- Heat transfer :

It's probably the must complex case. We have to determine not only material thermal parameters $(\lambda, \rho, c \ldots)$ but also conditions of heat exchange as boundary conditions between the forging piece and its environnement.

- Convection and radiation on free surface.

- Conduction and friction on contact between tool and piece. 


\section{CONSTITUTION OF AN EXPERIMENTAL DATABASE :}

Concerning these problems we can summarize the FORTECH/AIRFORGE approach with the figure 2 .

The FORTECH/AIRFORGE research and Development Department, ARDEM, works in close relationship with various public and industrial Research centers (CEMEF, INSA Lyon ...) and adapt their knowledge for specific industrial uses by performing preindustrial tests.

ARDEM has at its disposal a fully equipped experimental 300 tons press and a very interesting computer facilities. One of its major purpose is to constitute an experimental database concerning metallurgical behaviour according to thermomechanical history of the material. Anyway upsetting is a very efficient experimental way.

\section{ENERGY EXCHANGE BY RADIATION}

On the other way, some experimental investigations showed the importance of the radiation in a closed cavity (figure 3 ).

These results can be modelized by a numerical approach = this are confirm clearly that radiation is a fondamental phenomenon when we consider thermal boundary conditions for forging sequences (figure 4 ).

\section{INDUSTRIAL APPLICATIONS}

This type of approach is on development for several alloys and is one of our main topic. We can mention Nickel based superalliage as INC0718 and Waspaloy, and Titanium alloys as TA6V, Ti 17 and $6-2-4-2 / 6-2-4-6$

We give in figures 5 and 6 two examples of industrial applications concerning jet engine discs in INCO 718 (figure 5) and Ti 17 (figure 6).

\section{CONCLUSION}

Introduction of thermal parameters is a significant improvement in the field of computerized simulation of high sensitiv metallurgical allosy. To make it efficient, the forging manufacturer his to determine a wide range of experimental parameters describing its own forging process.

In these conditions, it is possible to apply modelisation to design of industrial piece. Informations obtained from the industrial process control show clearly that's necessary to take into account in a second step a more accurate description of the thermal phenomenon including radiation in closed cavity. 


\section{COMPUURER SIMUIATION}

\section{AND THERMOMECHUWVICAI PROCESS}

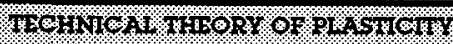

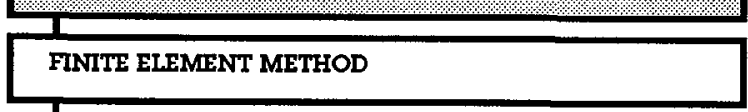

MATERIAL FLOW DURING DEFORMATION

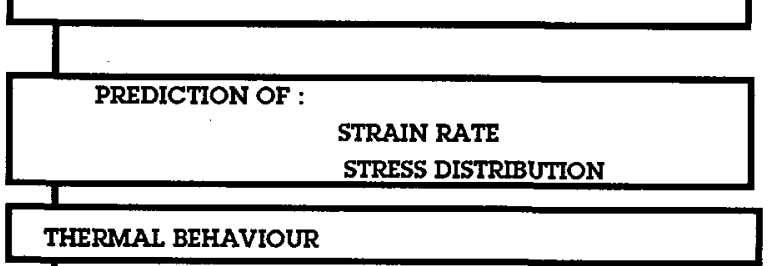

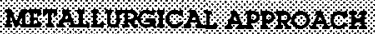

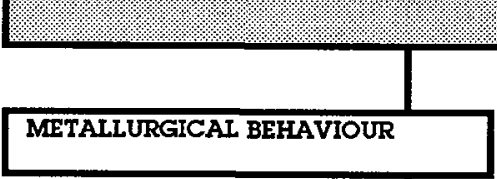

L

MICROSTRUCTURE AS A FUNCTION OF STRAIN AND TEMPERATURE

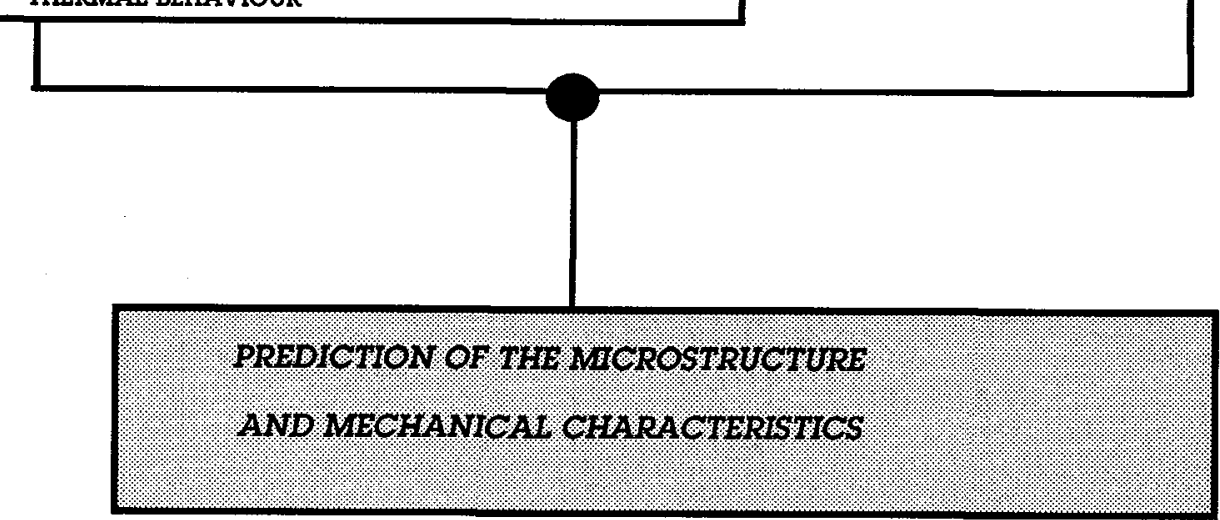

Figure 1

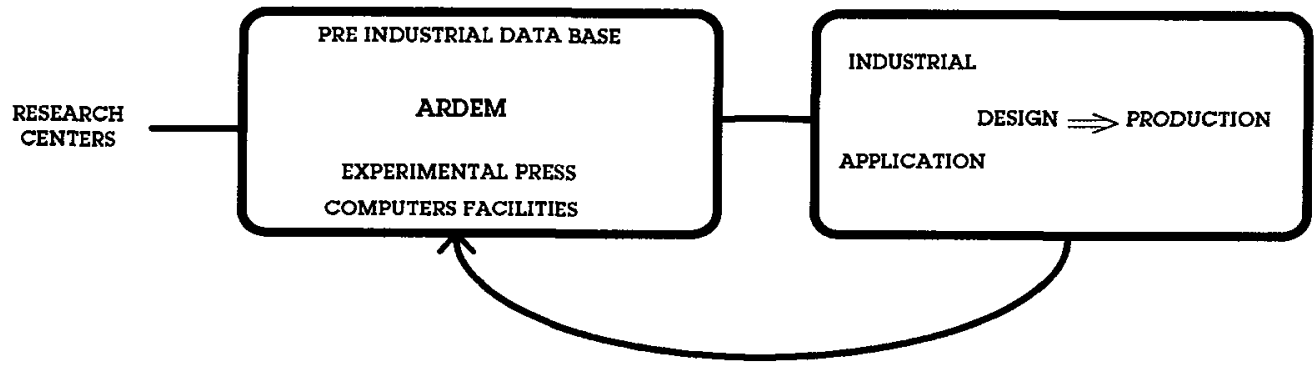

Figure 2 - FORTECH / AIRFORGE APPROACH 


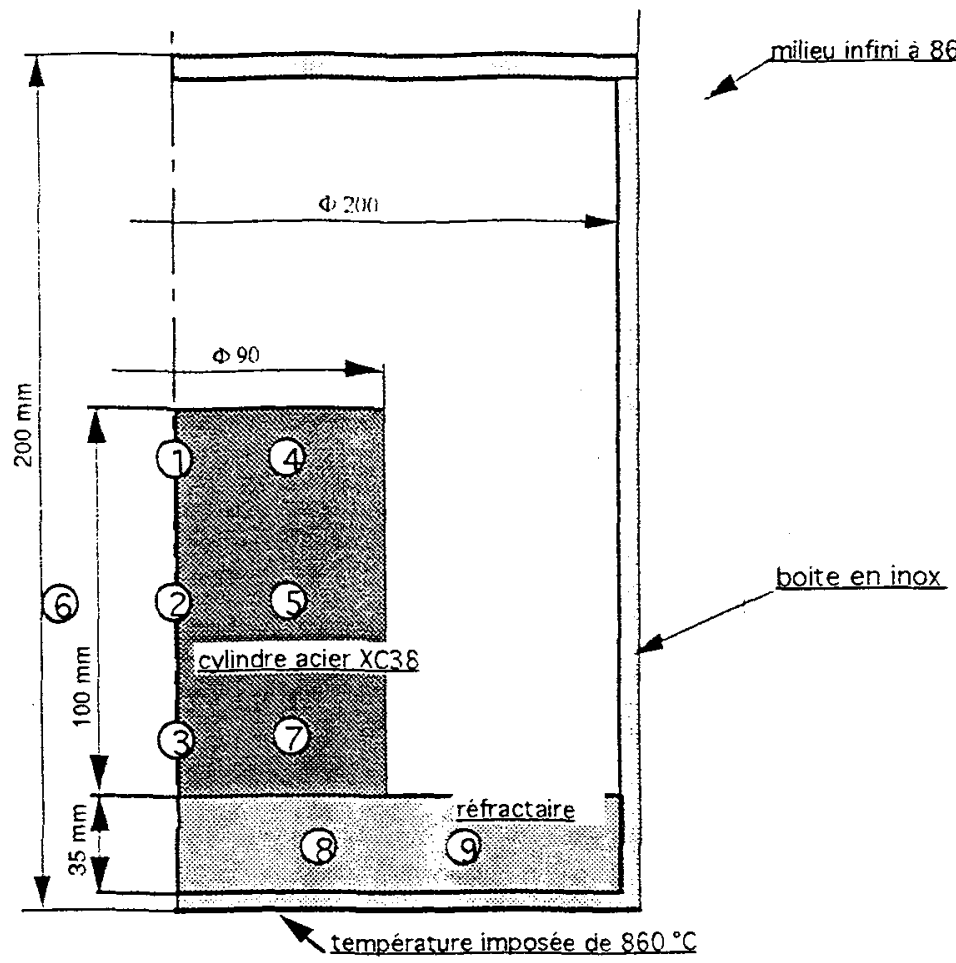

Figure 3 - Experimental installation

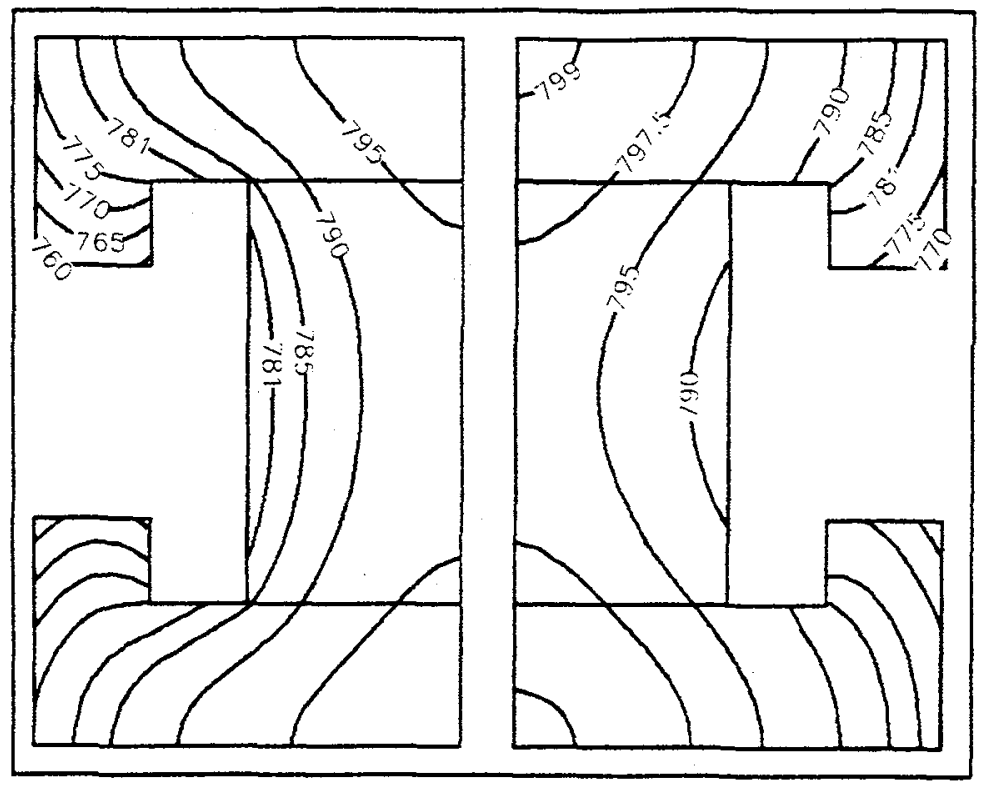

(a)

(b)

Figure 4 - Numerical calculation

(a) Whithout radiation (b) Taking into account radiation 
(C)mas

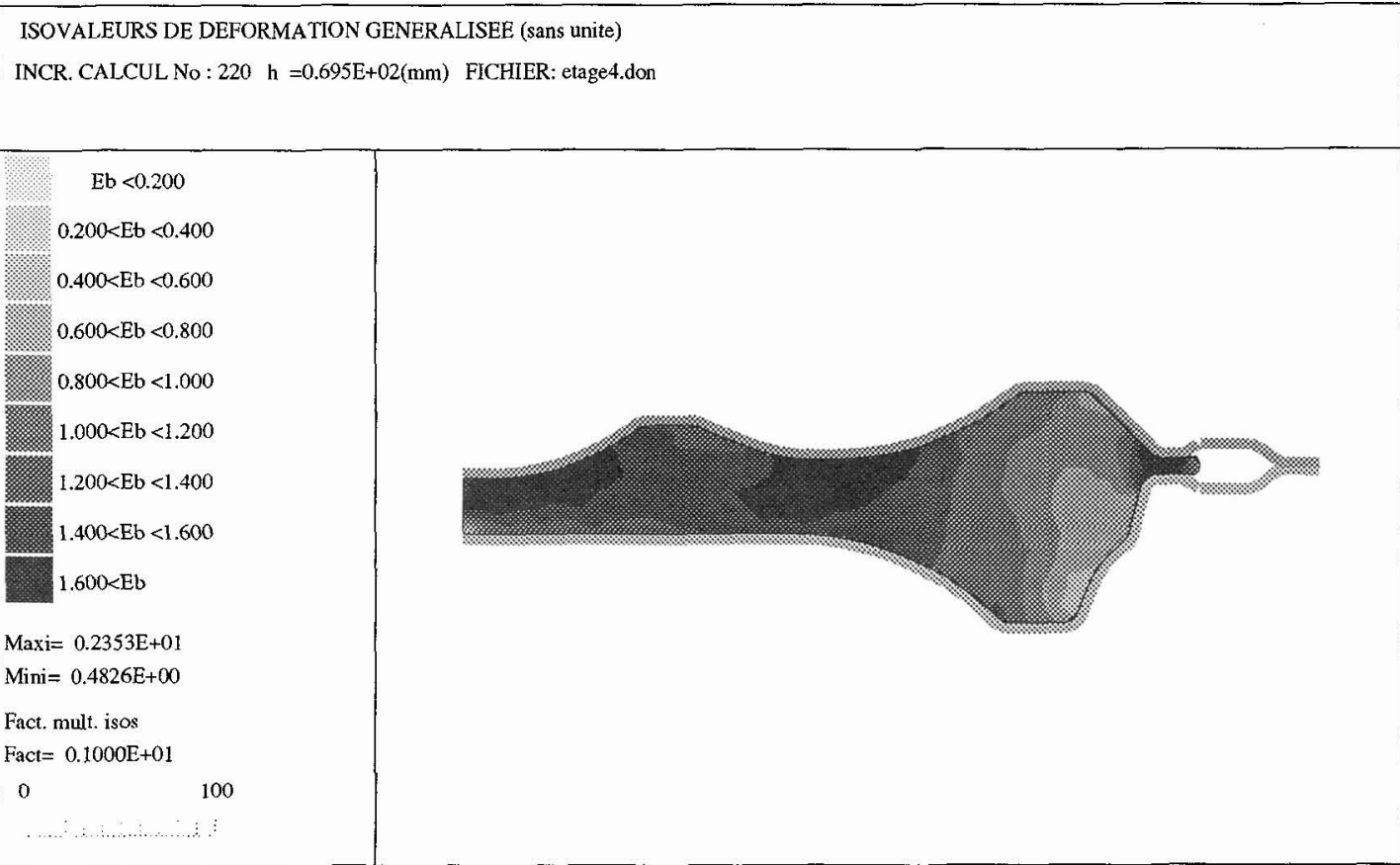

Figure 5 - INCO 718 - Small forged engine disc

C2mps

ISOVALEURS DE DEFORMATION GENERALISEE (sans unite)

INCR. CALCUL No: $145 \mathrm{~h}=0.120 \mathrm{E}+02(\mathrm{~mm})$ FICHIER: finition4.don

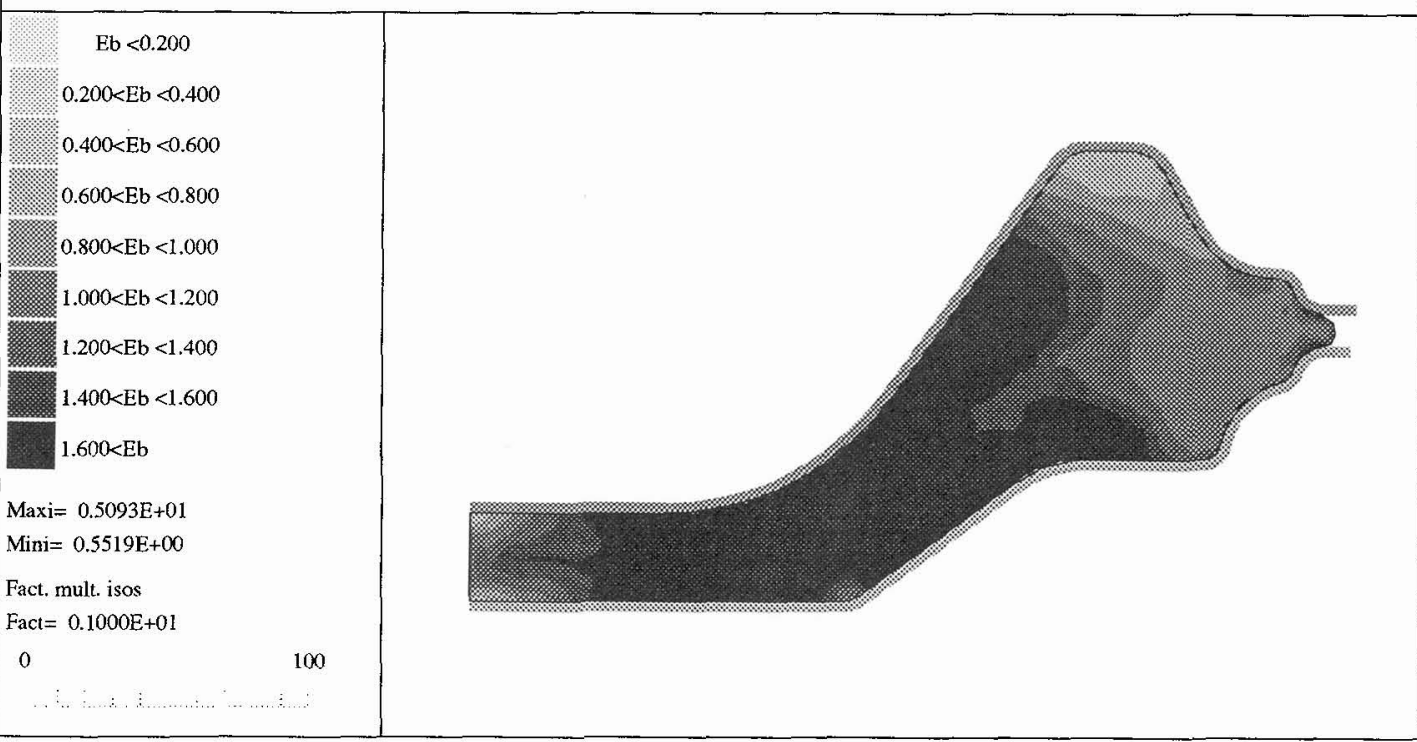

Date: 04-06-1993 16:22 Figure 6 - Ti 17 - large engine disc 